\title{
Unsafe disposal of faeces and its correlates among children under three years in Eswatini
}

\author{
M S Simelane, ${ }^{1} \mathrm{PhD}$; G B Chemhaka, ${ }^{1} \mathrm{PhD} ;$ T Maphosa,${ }^{2} \mathrm{PhD} ; \mathrm{E}$ Zwane, ${ }^{1} \mathrm{PhD}$ \\ ${ }^{1}$ Department of Statistics and Demography, Faculty of Social Sciences, University of Eswatini, Kwaluseni, Eswatini \\ ${ }^{2}$ Elizabeth Glaser Pediatric AIDS Foundation, Washington, United States of America
}

Corresponding author: M S Simelane (smasimelane@uniswa.sz)

\begin{abstract}
Background. It has long been established that human excreta contain over 50 pathogens that are transmitted via the faecal route, yet the common practice of unsafe disposal of children's faeces still persists in developing countries.

Objective. To identify the factors associated with unsafe disposal of children's faeces among children under three years of age in Eswatini. Methods. The study was based on combined data for the 2010 and 2014 Eswatini Multiple Indicator Cluster Surveys, from which 2765 children aged less than three years were included in the analysis. The analysis was based on logistic regression using weighted survey data.

Results. Overall, $41.8 \%$ of the childrens' faeces were disposed of unsafely. In the final multivariable logistic regression analysis, the odds of unsafe disposal of children's faeces were lower for households whose children were aged 12 months and older, compared with households whose children were under six months. Households with a pit latrine were less likely to dispose of child faeces unsafely, while the practice of unsafe disposal of children's faeces was more common in households with no toilet facility compared with those from households with a flush toilet. The practice of unsafe disposal of children's faeces was more common in urban areas than in rural areas. Regionally, lower odds of unsafe disposal of children's faeces were observed among households from the Manzini and Shiselweni regions, compared with those from the Lubombo region.

Conclusion. The study demonstrated that child age, toilet facilities, place of residence, and region of residence were associated with unsafe disposal of children's faeces.
\end{abstract}

S Afr J Child Health 2020;14(4):217-223. https://doi.org/10.7196/SAJCH.2020.v14i4.1726

The World Health Organization (WHO) has declared that sanitation is a basic human right. ${ }^{[1]}$ In the year 2012, over 2.5 billion people had poor sanitation and, of those, 1 billion practised open defecation. ${ }^{[2]}$ Nine out of 10 people who practise open defecation reside in rural areas. ${ }^{[2,3]}$ The problems of open defecation and unsafe faeces disposal pose many ramifications and affect all developing countries. ${ }^{[2]}$ It has long been established that human excreta contain over 50 pathogens that are transmitted via the faecal route. ${ }^{[4,5]}$ Therefore the practice of open defecation is a major cause of diarrhoeal diseases, especially among children $<5$ years old. ${ }^{[6]}$ In 2013 , over 800000 children $<5$ years died of related diarrhoeal diseases; in 2015, 688 million children $<5$ were reported to be sick from diarrhoea, and almost half a million died as a result of diarrhoea. ${ }^{[7,8]}$ Even though a decline of child mortality owing to diarrhoea has been noted globally, subSaharan countries still lag behind. ${ }^{[7]}$

Regardless of the known risks posed by unsafe disposal of child faeces, the issue has received less attention from public health programmes and interventions aimed at eliminating diarrhoea. ${ }^{[4,5]}$ There is a wide misconception that child faeces contain less or no pathogens relative to adults. ${ }^{[4]}$ Children are in fact more susceptible to faecal infections owing to their behaviour; they crawl and ingest contaminated substances, which include stools. ${ }^{[9]}$

There should be more efforts and programmes that prioritise child faeces disposal (as toilet facilities are not designed to be used by young children), which is in line with the global agenda on Sustainable Development Goals (SDGs), item 6, that by 2030 there should be improved access to sanitation and hygiene for all and an end to open defecation. ${ }^{[10]}$ The WHO classifies child stool disposal as safe if the child uses a toilet or latrine and the faeces are put/ rinsed into a toilet or latrine; child stools that are left in the open or buried, rinsed in a drain or ditch or put in the garbage are classified as disposed of unsafely. ${ }^{[11]}$

Among the studies that investigated child faeces disposal, many found that the age of the child, maternal age, maternal education, household wealth index, number of children $<5$ years in the household, availability of toilet facilities, region, and place of residence were associated with child faeces disposal practices. ${ }^{[12,13]}$ In Eswatini, few or no inferential studies have been conducted to ascertain the factors associated with child faeces disposal, apart from descriptive reports that demonstrate the magnitude of the problem. ${ }^{[14,15]}$ In 2010 , only $60 \%$ of households reported disposing of child faeces safely while, in 2014 , about $55 \%$ of children aged $<2$ years had their faeces disposed of safely. ${ }^{[14,15]}$ The factors associated with child faeces disposal in Eswatini have not yet been investigated and, to be able to address the problem through proper interventions, it is essential that they are. Therefore, the present study aimed to identify the factors associated with unsafe disposal of children's faeces to assist public health specialists in designing evidence-based programmes and policies.

\section{Methods}

\section{Study design and data source}

The present study was a secondary analysis of combined data from the Eswatini 2010 and 2014 Multiple Indicator Cluster Surveys (MICSs). The MICS is a global cross-sectional study design with a nationally representative sample conducted by the United Nations 
Children's Fund (UNICEF) to assist countries in monitoring and tracking indicators on children's, women's and men's health and development in developing countries. The MICS uses standardised structured survey questionnaires administered through face-to-face interviews at the household level. ${ }^{[16]}$

\section{Sampling design and study samples}

A two-staged sampling strategy was applied and enumeration areas (EAs) were sampled using a systematic random sampling method; 15 households from each EA were further randomly selected. Sampling was done so as to be representative of the four regions in Eswatini, which are Hhohho, Manzini, Shiselweni and Lubombo. To get information on children aged $<5$ years, their mothers or caregivers aged 15 - 49 years were interviewed, and a $95.2 \%$ response rate was achieved in the 2014 survey, while a response rate of $95 \%$ was achieved in 2010 . ${ }^{[15}$

The combined survey data analysis comprised a total of 9699 households, 4762 women/caregivers aged 15 - 49, and a total of 5340 children aged $<5$ years who completed the survey. However, the question on child faeces disposal was asked only for children $<3$ years, who made up a total of 3174 in the dataset. The study sample included 2765 children $<3$ years with complete information concerning their faecal disposal.

\section{Variables}

Dependent variable: The outcome variable of child faeces disposal was constructed based on the WHO definition. ${ }^{[11]}$ Mothers or caregivers of children were asked, 'The last time the child passed faeces, what was done to dispose of them?' Several responses included 'The child used the toilet or latrine; put/rinsed into the toilet or latrine; put/rinsed into a drain or ditch; thrown into the garbage (solid waste); buried; left in the open. ${ }^{\text {'[14] }}$ The outcome variable was generated to a dichotomous variable: unsafe (1) (put/rinsed into a drain or ditch, thrown into the garbage, left in the open, buried, other); and safe (0) (child used toilet or latrine and child faeces put/rinsed into toilet or latrine).

Explanatory variables: The literature was used to select the independent variables from the MICS dataset and included: age of the child; child sex; maternal age; maternal education level; marital status; listen to the radio; read the newspaper; watch television; toilet facility; shared toilet with neighbours; number of children under five years; child diarrhoea morbidity in the past two weeks preceding the survey; household wealth index; source of water in the household; place of residence; and region of residence.

\section{Statistical analysis}

Stata 15 (StataCorp.; USA) was used to perform descriptive and inferential analysis. The svy command was used to weight the analysis adjusting for the survey sampling design. First, a univariable analysis was performed to estimate the weighted sample distribution. A weighted bivariable analysis through cross-tabulation to test the crude relationship between each explanatory factor and unsafe disposal of child faeces along with the $\chi^{2}$ test, was used. A multi-collinearity test was done, and there were no variables with variance inflation factor (VIF) of greater than 10. Furthermore, bivariable logistic regression was used. At this stage, the study computed crude odds ratios (CORs) and their 95\% confidence interval (CI.) All variables that were significant at $5 \%$ in the bivariable models were included in the multivariable model. ${ }^{[17]}$ Finally, a weighted multivariable binary logistic regression model was used to control for the effects of other covariates in the model. In the final model, results were reported using adjusted odds ratios (aORs) and 95\% CIs.

\section{Ethical considerations}

The study dataset is publicly available on the UNICEF website and participants' identifiers were de-identified before being posted in the UNICEF data repository. Ethical compliance was obtained by the Eswatini Central Statistics Office during implementation of the survey, including an application for protocol approval from the Eswatini health and human research review board (EHHRRB).

\section{Results \\ Socio-demographic characteristics}

Of the total children included in the analysis, about half (50.9\%) were female and $21.5 \%$ had had diarrhoea in the previous two weeks before the survey. A majority (41.2\%) of the children were born to mothers aged 25 - 34, married (56\%), with secondary education (34.2\%). About seven out of 10 were from households that used a pit latrine, and a majority (67.8\%) from households that used unimproved water sources and were from rural areas (75.3\%) and residents in the Manzini region (35.6\%) (Table 1).

\section{Prevalence of child faeces disposal sites in Eswatini}

Overall, $41.8 \%$ of the childrens' faeces were disposed of unsafely. A majority (48.9\%) of the children's' faeces were put or rinsed into a toilet or latrine, while only $9.3 \%$ of the children's faeces were disposed of in a toilet or latrine, and $15.5 \%$ were put into the garbage. About $8.9 \%$ of the childrens' faeces were buried, while $8.5 \%$ were left in the open (Table 2).

\section{Prevalence of unsafe child faeces by characteristics}

Table 3 shows the prevalence of child faeces disposal by explanatory variables. The results show a significantly higher proportion (34.5\%) of unsafe disposal of children's faeces among children aged 12 - 24 months v. $18.8 \%$ among children aged 6 - 11 months $(p=0.006)$. A significantly higher proportion $(48.9 \%)$ of unsafe disposal of children's faeces among children was from households with a pit latrine v. only $19 \%$ with a flush toilet $(p<0.001)$. Slightly below a third $(31.4 \%)$ of child faeces were disposed of unsafely by mothers with secondary education, while $8 \%$ had no level of formal education $(p=0.001)$. A majority of the households (64.3\%) that disposed of child faeces unsafely had improved water sources v. those with unimproved water sources $(35.7 \%)$ $(p<0.001)$. Consideration of the households' wealth index revealed that a higher proportion (44.5\%) of poor households disposed of child faeces unsafely v. $13.5 \%$ among households classified under the middle quintile $(p<0.001)$. The practice was more prevalent in the Manzini region, where the majority (29.9\%) of children's stools were reported to be disposed of unsafely v. $19.8 \%$ in the Shiselweni region $(p<0.001)$ (Table 3$)$.

\section{Factors associated with unsafe disposal of children's faeces}

Table 4 shows the results of the bivariable and multivariable logistic regression. The bivariable model results (Table 4) show that child age, maternal education, toilet facility, source of water supply, household wealth index, and region of residence were associated with unsafe disposal of children's faeces.

In the multivariable logistic regression analysis, the odds of disposing of child faeces unsafely were lower for households whose children were aged 12 - 24 months $(\mathrm{aOR}=0.61 ; 95 \%$ CI 0.46 - 0.82) and aged 25 - 35 months $(\mathrm{aOR}=0.49 ; 95 \%$ CI $0.34-0.70)$ compared with households whose children were aged $<6$ months. Households with a pit latrine were less likely to dispose of child faeces unsafely 
Table 1. Descriptive statistics of study participants $(N=2765)$

Characteristics

Age of child (months)

$<6$

$6-11$

$12-24$

$25-35$

Sex

Male

Female

Diarrhoea last 2 weeks

Yes

No

Maternal age (years)

$15-24$

$25-34$

$\geq 35$

Marital status

Married

Formerly married

Never married

Toilet facility

Flush toilet

Pit latrine

No facility

Share toilet with neighbours $(n=2$ 308)

Yes

No

Maternal education

None

Primary

Secondary

High school

Tertiary

Listen to radio ( $n=1401$ )

Yes

No

Read newspaper ( $n=1$ 300)

Yes

No

Watch television ( $n=1401)$

Yes

No

Number of children $<5$ years

1

$2-3$

$\geq 4$

Source of water supply

Improved

Unimproved

Household wealth index

Poor

Middle

Rich
Weighted $n(\%)$

$486(18.0)$

486 (17.4)

977 (34.8)

816 (29.9)

1360 (49.1)

1405 (50.9)

601 (21.5)

2164 (78.5)

1073 (38.6)

1112 (41.2)

$580(20.2)$

$1541(56.0)$

206 (7.5)

1018 (36.4)

362 (13.9)

1945 (70.9)

458 (15.2)

885 (41.0)

1423 (59.0)

172 (5.9)

800 (29.0)

960 (34.2)

653 (24.1)

180 (6.8)

983 (70.7)

418 (29.3)

741 (61.4)

559 (38.6)

$682(53.0)$

719 (47.0)

1331 (49.3)

1241 (43.8)

193 (6.9)

$958(32.2)$

1807 (67.8)

$1276(43.9)$

$586(20.1)$

903 (35.9)

...continued
Table 1.(continued) Descriptive statistics of study participants $(N=2765)$

\begin{tabular}{ll}
\hline Characteristics & Weighted $\boldsymbol{n}(\%)$ \\
\hline Place of residence & \\
Rural & $2119(75.3)$ \\
Urban & $646(24.7)$ \\
Region & \\
Hhohho & $658(24.2)$ \\
Manzini & $755(35.6)$ \\
Shiselweni & $738(20.9)$ \\
Lubombo & $614(19.3)$
\end{tabular}

Table 2. Weighted prevalence of child faeces disposal in Eswatini $(N=2765)$

\begin{tabular}{llll}
\hline $\begin{array}{l}\text { Child faeces disposal } \\
\text { practice }\end{array}$ & $\begin{array}{l}\text { Weighted } \\
\text { frequency }\end{array}$ & $\begin{array}{l}\text { Weighted } \\
\text { percentage }\end{array}$ & 95\% CI \\
\hline $\begin{array}{l}\text { Used toilet/latrine } \\
\text { Put/rinsed in toilet/latrine }\end{array}$ & 1348 & 9.3 & $7.7-11.1$ \\
$\begin{array}{l}\text { Put/rinsed into drain } \\
\text { or ditch }\end{array}$ & 222 & 7.7 & $46.2-51.6$ \\
Put into garbage & 416 & 15.5 & $6.6-8.9$ \\
Buried & 268 & 8.9 & $13.8-17.4$ \\
Left in the open & 251 & 8.5 & $7.6-10.4$ \\
Other & 38 & 1.2 & $0.9-9.8$ \\
Overall child stool disposal & & & \\
$\quad$ Safe & 1570 & 58.2 & $55.6-60.7$ \\
$\quad$ Unsafe & 1195 & 41.8 & $39.3-44.4$ \\
CI $=$ confidence interval. & & &
\end{tabular}

(aOR 0.31 ; 95\% CI 0.21 - 0.47), while those from households with no toilet facility were more likely to dispose of child faeces unsafely (aOR 5.61; 95\% CI 3.15 - 9.99) compared with households with a flush toilet. Child faeces were more likely to be disposed of unsafely in households located in urban areas (aOR 1.47; 95\% CI 1.12 - 1.97) compared with households in rural areas. This study further showed a statistical association between region of residence and unsafe disposal of children's faeces. For example, lower odds of unsafe disposal of children's faeces were observed among households from the Manzini region (aOR 0.62; 95\% CI 0.47 - 0.83) and the Shiselweni region (aOR 0.69; 95\% CI 0.53 - 0.93) compared with those from the Lubombo region.

\section{Discussion}

The study found that, overall, $41.8 \%$ of the children had their stools disposed of unsafely and that several determinants accounted for the practice. The high practice of disposing of child faeces unsafely requires careful attention and effective programmes if SDG number 6 of achieving improved access to sanitation and hygiene for all and an end to open defecation is to be realised by $2030 .{ }^{[10]}$ The prevalence of unsafe disposal of children's faeces is relatively similar to the prevalence reported in Nigeria; ${ }^{[18]}$ however, it is lower in Kenya ${ }^{[19]}$ and higher in Madagascar. ${ }^{[20]}$ The present study found that the most common method of disposing child faeces unsafely was in garbage, which implies that a significant volume of child faeces disposed of unsafely in garbage may come into contact with humans and animals. ${ }^{[21]}$ Other studies have reported that waste disposal in garbage was common. ${ }^{[22,23]}$ Human excreta carry over 
Table 3. Prevalence of child faeces disposal by characteristics

\begin{tabular}{|c|c|c|c|}
\hline \multirow[b]{2}{*}{ Characteristics } & \multicolumn{2}{|c|}{ Child faeces disposal } & \multirow[b]{2}{*}{$p$-value ${ }^{\star}$} \\
\hline & Unsafe, $n(\%)$ & Safe, $n(\%)$ & \\
\hline Age of child (months) & & & $0.006(12.49)$ \\
\hline$<6$ & $234(21.1)$ & $252(15.7)$ & \\
\hline $6-11$ & $224(18.8)$ & $262(16.3)$ & \\
\hline $12-24$ & $419(34.5)$ & $558(35.0)$ & \\
\hline $25-35$ & $318(25.6)$ & $498(33.0)$ & \\
\hline Sex & & & $0.804(0.06)$ \\
\hline Male & $591(50.2)$ & $769(48.3)$ & \\
\hline Female & $604(49.8)$ & $801(51.7)$ & \\
\hline \multicolumn{4}{|l|}{ Diarrhea last two weeks } \\
\hline Yes & $273(23.5)$ & $328(20.1)$ & \\
\hline No & $922(76.5)$ & $1242(79.9)$ & \\
\hline Maternal age (years) & & & $0.798(0.45)$ \\
\hline $15-24$ & $457(39.2)$ & $616(38.2)$ & \\
\hline $25-34$ & $489(40.8)$ & $623(41.4)$ & \\
\hline$\geq 35$ & $249(20.0)$ & $331(20.3)$ & \\
\hline Marital status & & & $0.173(3.51)$ \\
\hline Married & $667(55.9)$ & $874(56.2)$ & \\
\hline Formerly married & $101(8.7)$ & $105(6.7)$ & \\
\hline Never married & $427(35.5)$ & $591(37.2)$ & \\
\hline Toilet facility & & & $<0.001(567.96)$ \\
\hline Flush toilet & $217(19.0)$ & $145(10.3)$ & \\
\hline Pit latrine & $574(48.9)$ & $1371(86.7)$ & \\
\hline No facility & $404(32.1)$ & $54(3.0)$ & \\
\hline Share toilet with neighbours & & & $0.382(0.764)$ \\
\hline Yes & $313(42.1)$ & $572(40.4)$ & \\
\hline No & $478(57.9)$ & $945(59.6)$ & \\
\hline Maternal education & & & $<0.001(37.13)$ \\
\hline None & $103(8.0)$ & $69(4.3)$ & \\
\hline Primary & $367(30.4)$ & $433(27.6)$ & \\
\hline Secondary & $366(31.4)$ & $594(36.4)$ & \\
\hline High school & $268(22.1)$ & $385(25.8)$ & \\
\hline Tertiary & & & \\
\hline Listen to radio & & & $0.088(2.91)$ \\
\hline Yes & $431(67.8)$ & $552(73.0)$ & \\
\hline No & $204(32.2)$ & $214(27.0)$ & \\
\hline Read newspaper & & & $0.497(0.46)$ \\
\hline Yes & $324(59.8)$ & $417(62.6)$ & \\
\hline No & $255(40.2)$ & $304(37.4)$ & \\
\hline Watch television & & & $0.105(2.63)$ \\
\hline Yes & $294(50.4)$ & $388(55.2)$ & \\
\hline No & $341(49.6)$ & $378(44.8)$ & \\
\hline Children $<5$ years, $n$ & & & $0.873(0.27)$ \\
\hline 1 & $570(49.1)$ & $761(49.5)$ & \\
\hline $2-3$ & $543(44.1)$ & $698(43.5)$ & \\
\hline$\geq 4$ & $82(6.8)$ & $111(7.0)$ & \\
\hline Source of water supply & & & $<0.001(14.36$ \\
\hline Improved & $734(64.3)$ & $1073(70.4)$ & \\
\hline Unimproved & $461(35.7)$ & $497(29.6)$ & \\
\hline Household wealth index & & & $<0.001(15.81)$ \\
\hline Poor & $537(44.5)$ & $531(32.9)$ & \\
\hline Middle & $163(13.5)$ & $274(16.7)$ & \\
\hline Rich & $495(42.0)$ & $765(50.4)$ & \\
\hline
\end{tabular}


Table 3. (continued) Prevalence of child faeces disposal by characteristics

\begin{tabular}{llll}
\hline & \multicolumn{2}{c}{ Child faeces disposal } & \\
\cline { 2 - 3 } Characteristics & Unsafe, $\boldsymbol{n}(\%)$ & Safe, $\boldsymbol{n}(\%)$ & $0.072(3.23)$ \\
\hline Place of residence & & & \\
\hline Rural & $896(74.1)$ & $1223(76.1)$ & \\
Urban & $299(25.9)$ & $347(23.9)$ & $<0.001(57.48)$ \\
Region & & & \\
Hhohho & $287(24.3)$ & $371(24.1)$ & \\
Manzini & $263(29.9)$ & $492(39.6)$ & \\
Shiselweni & $307(19.8)$ & $271(21.7)$ & \\
Lubombo & $338(26.0)$ & &
\end{tabular}

Table 4. Bivariable and multivariable analysis of factors associated with unsafe disposal of children's faeces

\begin{tabular}{|c|c|c|}
\hline Characteristics & cOR $(95 \% \mathrm{CI})$ & aOR $(95 \% \mathrm{CI})$ \\
\hline \multicolumn{3}{|l|}{ Age of child (months) } \\
\hline$<6$ & 1 & 1 \\
\hline $6-11$ & $0.86(0.64-1.14)$ & $0.80(0.57-1.10)$ \\
\hline $12-24$ & $0.73(0.57-0.94)^{*}$ & $0.61(0.46-0.82)^{*}$ \\
\hline $25-35$ & $0.58(0.43-0.78)^{\star}$ & $0.49(0.34-0.70)^{*}$ \\
\hline \multicolumn{3}{|l|}{ Sex } \\
\hline Male & 1 & \\
\hline Female & $0.93(0.77-1.11)$ & \\
\hline \multicolumn{3}{|c|}{ Diarrhoea last 2 weeks } \\
\hline Yes & 1 & \\
\hline No & $0.82(0.66-1.02)$ & \\
\hline \multicolumn{3}{|l|}{ Maternal age (years) } \\
\hline $15-24$ & 1 & \\
\hline $25-34$ & $0.96(0.76-1.21)$ & \\
\hline$\geq 35$ & $0.96(0.74-1.24)$ & \\
\hline \multicolumn{3}{|l|}{ Marital status } \\
\hline Married & 1 & \\
\hline Formerly married & $1.31(0.88-1.93)$ & \\
\hline Never married & $0.96(0.79-1.17)$ & \\
\hline \multicolumn{3}{|l|}{ Maternal education } \\
\hline None & & 1 \\
\hline Primary & $0.60(0.40-0.91)^{\star}$ & $0.88(0.55-1.42)$ \\
\hline Secondary & $0.47(0.30-0.72)^{*}$ & $0.95(0.58-1.55)$ \\
\hline High school & $0.47(0.30-0.72)^{\star}$ & $1.00(0.60-1.67)$ \\
\hline Tertiary & $0.75(0.44-1.26)$ & $1.12(0.60-2.08)$ \\
\hline \multicolumn{3}{|l|}{ Toilet facility } \\
\hline Flush toilet & 1 & 1 \\
\hline Pit latrine & $0.31(0.23-0.40)^{*}$ & $0.31(0.21-0.47)^{*}$ \\
\hline No facility & $5.78(3.74-8.92)^{*}$ & $5.61(3.15-9.99)^{*}$ \\
\hline \multicolumn{3}{|c|}{ Share toilet with neighbours } \\
\hline Yes & 1 & \\
\hline No & $0.93(0.75-1.15)$ & \\
\hline
\end{tabular}

...continued

50 pathogens and predispose children to several infections such as diarrhoea. ${ }^{[12,24]}$ A cross-sectional study in Indonesia found that the odds of diarrhoea were higher among children whose stools were disposed of unsafely than among those whose stools were disposed of safely. ${ }^{[25]}$
Table 4. (continued) Bivariable and multivariable analysis of factors associated with unsafe disposal of children's faeces

\begin{tabular}{|c|c|c|}
\hline Characteristics & $\operatorname{cOR}(95 \% \mathrm{CI})$ & $\mathrm{aOR}(95 \% \mathrm{CI})$ \\
\hline \multicolumn{3}{|l|}{ Listen to radio } \\
\hline Yes & \multicolumn{2}{|l|}{1} \\
\hline No & \multicolumn{2}{|l|}{$1.28(0.92-1.78)$} \\
\hline \multicolumn{3}{|l|}{ Read newspaper } \\
\hline \multicolumn{3}{|l|}{ Yes } \\
\hline No & \multicolumn{2}{|l|}{$1.13(0.87-1.47)$} \\
\hline \multicolumn{3}{|l|}{ Watch television } \\
\hline Yes & \multicolumn{2}{|c|}{1} \\
\hline No & \multicolumn{2}{|l|}{$121(0.95-1.54)$} \\
\hline \multicolumn{3}{|l|}{ Children $<5$ years, $n$} \\
\hline 1 & \multicolumn{2}{|l|}{1} \\
\hline $2-3$ & \multicolumn{2}{|l|}{$1.02(0.85-1.22)$} \\
\hline$\geq 4$ & \multicolumn{2}{|l|}{$0.98(0.64-1.49)$} \\
\hline \multicolumn{3}{|l|}{ Source of water supply } \\
\hline Improved & 1 & 1 \\
\hline Unimproved & $1.32(1.09-1.59)^{*}$ & $1.25(1.00-1.55)$ \\
\hline \multicolumn{3}{|l|}{ Household wealth index } \\
\hline Poor & 1 & 1 \\
\hline Middle & $0.57(0.45-0.72)^{\star}$ & $1.06(0.82-1.38)$ \\
\hline Rich & $0.66(0.54-0.80)^{*}$ & $0.83(0.62-1.10)$ \\
\hline \multicolumn{3}{|l|}{ Place of residence } \\
\hline Rural & 1 & 1 \\
\hline Urban & $1.11(0.89-1.40)$ & $1.47(1.12-1.97)^{\star}$ \\
\hline \multicolumn{3}{|l|}{ Region } \\
\hline Hhohho & $0.56(0.43-0.74)^{*}$ & $0.84(0.62-1.14)$ \\
\hline Manzini & $0.42(0.33-0.55)^{\star}$ & $0.62(0.47-0.83)^{*}$ \\
\hline Shiselweni & $0.51(0.39-0.67)^{*}$ & $0.69(0.53-0.93)^{\star}$ \\
\hline Lubombo & 1 & 1 \\
\hline Observations & & 2765 \\
\hline Model goodness-of-fit & & 0.2782 \\
\hline
\end{tabular}

In the present study, the odds of child faeces disposed of unsafely were lower with increased age of the children. For example, children aged $\geq 12$ months had lower odds of their faeces being disposed of unsafely. The study finding is consistent with the literature ${ }^{[3,13]}$ which could be because younger children's faeces 
are regarded as being less harmful and containing less visible food residuals, which may be less repellent than those of older children and adults, and hence not disposed of properly.

Several studies have shown that households with an improved type of toilet facility were less likely to unsafely dispose of child faeces. ${ }^{[12,26]}$ The present study found that households with a pit latrine had lower odds of disposing of child faeces unsafely, and those with no toilet facility were more likely to dispose of child faeces unsafely than those with a flush toilet. This behaviour could be because lack of toilet facilities results in undisposed child faeces. ${ }^{[27]}$

Evidence suggests a positive relationship between improved household water supply and the practice of disposing of child faeces unsafely. ${ }^{[28,29]}$ However, our study found no significant association between the type of water source and the unsafe disposal of child faeces after controlling for other factors. The availability of improved water in the household may be a great motivation for mothers to maintain good hygiene, including safe child faeces disposal and handwashing behaviour. Similarly, other studies found no association between improved water sources and child faeces disposal. ${ }^{[12,13]}$

The urban-rural disparity in hygiene behaviour has long been established in the literature. ${ }^{[1,30]}$ Other studies reported lower odds of the practice of disposing of child faeces unsafely in urban areas compared with rural areas. ${ }^{[12,13]}$ In contrast, we found higher odds of unsafe disposal of children's faeces in urban areas than in rural areas; this could be explained by the fact that in Eswatini, the majority of households that disposed of child stools in a pit latrine are in rural areas, compared with flush toilets in urban areas. In our study, households with a pit toilet were less likely to dispose of child faeces unsafely than did households with a flush toilet (Table 4). A higher proportion of households used pit latrines to dispose of waste material. ${ }^{[14]}$

Several studies found a significant variation in the disposal of child faeces unsafely across the regions of residence. ${ }^{[13,31]}$ The present study found lower odds of the disposal of child faeces unsafely in the Manzini and Shiselweni regions compared with the Lubombo region. A possible explanation could be that the two regions are better developed with better sanitation facilities and educated mothers/caregivers than in the Lubombo region.

\section{Study limitations}

Our study had several limitations. It is cross-sectional and therefore more prone to confounding. However, the study controlled for several confounders in the multivariable model. Generally, cross-sectional studies, including this one, lack evidence on temporality; hence, the study cannot establish if the exposure caused the outcome. ${ }^{[32]}$ Desirability bias can also not be ruled out, as participants may have misreported the practice of child faeces disposal. However, the limitations of the study could not outweigh the strength of the study, as the data were sourced from the international MICS programme.

\section{Conclusion}

The unsafe disposal of child faeces remains a public health problem in Eswatini. The present study demonstrated that child age, type of toilet facility, place of residence, and region of residence were associated with unsafe disposal of children's faeces. Programmes that aim to address the problem of unsafe disposal of children's faeces and improve sanitation in Eswatini should target children younger than six months from households with no toilet facility, residents in urban areas, and those from the Lubombo region. The findings also campaign for further research to identify effective strategies to reduce unsafe disposal of children's faeces in Eswatini.

\section{Declaration. None.}

Acknowledgements. The authors would like to thank the Multiple Indicator Cluster Survey team for providing access to the datasets.

Author contributions. MSS conceived the research idea, performed the statistical analysis, and prepared the initial draft of the manuscript. GBC, TM and EZ critically reviewed the manuscript and contributed to the study design and manuscript writing. All authors reviewed and approved the final manuscript.

Funding. None.

Conflicts of interest. None.

1. World Health Organization, UNICEF. Joint Monitoring Programme for Water Supply and Sanitation. Progress on Sanitation and Drinking Water: 2015 Update. Geneva, Switzerland: WHO, 2015. https://www.who.int/water_sanitation health/publications/9789241563956/en/ (accessed 24 October 2019).

2. World Health Organization, UNICEF. Joint Water Supply Sanitation Monitoring Programme. Progress on drinking water and sanitation: 2014 Update. Geneva Switzerland: WHO, 2014. https://www.who.int/water_sanitation_health/ publications/2014/jmp-report/en/ (accessed 12 March 2020).

3. Islam M, Ercumen A, Ashraf S, et al. Unsafe disposal of feces of children $<3$ years among households with latrine access in rural Bangladesh: Association with household characteristics, fly presence and child diarrhea. PLoS One 2018;13(4):e0195218. https://doi.org/10.1371\%2Fjournal.pone.0195218

4. Brown J, Cairncross S, Ensink JHJ. Water, sanitation, hygiene, and enteric infections in children. Arch Dis Child 2013;98(8):629-634. https://doi. org/10.1136/archdischild-2011-301528

5. Mara D, Lane J, Scott B, Trouba D. Sanitation, and health. PLoS Medicine 2010;7(11):e1000363. https://doi.org/10.1371/journal.pmed

6. UNICEF. One is too many: Ending child deaths from pneumonia and diarrhea. New York: UNICEF, 2016. https://data.unicef.org/wp-content/ uploads/2016/11/UNICEF-Pneumonia-Diarrhoea-report2016-web-version. pdf (accessed 24 December 2019).

7. Vos T, Allen C, Arora $M$, et al. Global, regional, and national incidence, prevalence, and years lived with disability for 310 diseases and injuries, 19902015: A systematic analysis for the Global Burden of Disease Study 2015. Lancet 2016;388(10053):1545-1602. https://doi.org/10.1016/s0140-6736(16)31678-6

8. World Health Organization. The World Health Report: 2005: Make Every Mother and Child Count. Geneva: WHO, 2015. https://www.who.int/ whr/2005/en/ (accessed 30 September 2019).

9. World Health Organization, United Nations Children's Fund. Core questions on drinking water and sanitation for household surveys. Geneva: WHO, 2006. https://apps.who.int/iris/handle/10665/43489 (accessed 30 September 2019).

10. United Nations. Transforming Our World: The 2030 Agenda for Sustainable Development. New York: United Nations, 2015. https://sustainabledevelopment. un.org/post2015/transformingourworld (accessed 20 0ctober 2019).

11. World Health Organization. Guidelines on sanitation and health. Geneva: WHO, 2018. https://www.who.int/water_ sanitation_health/publications/ guidelines-on-sanitation-and-health/en/ (accessed 16 October 2019).

12. Azage M, Haile D. Factors associated with safe child feces disposal practices in Ethiopia: Evidence from demographic and health survey. Arch Public Health 2015;73:40. https://doi.org/10.1186\%2Fs13690-015-0090-Z

13. Sahiledengle B. Prevalence and associated factors of safe and improved infant and young children stool disposal in Ethiopia: Evidence from demographic and health survey. BMC Public Health. 2019;19(1):970. https://doi.org/10.1186/ s12889-019-7325-9

14. Central Statistical Office, UNICEF. Eswatini Multiple Indicator Cluster Survey 2014. Final Report. Mbabane, Eswatini, Central Statistical Office, and UNICEF, 2016. https://mics-surveys-prod.s3.amazonaws.com/MICS5/Eastern\%20and\%20 Southern\%20Africa/Eswatini/2014/Key\%20findings/Swaziland\%202014\%20 MICS\%20KFR_English.pdf (accessed 24 October 2019).

15. Central Statistical Office, UNICEF. Eswatini Multiple Indicator Cluster Survey 2010. Final Report. Mbabane, Eswatini, Central Statistical Office, and UNICEF, 2011. https://reliefweb.int/report/swaziland/swaziland-multiple-indicator-cluster-survey-2010-final-report (accessed 15 April 2020).

16. UNICEF. Statistics and Monitoring: Multiple Indicator Cluster Survey (MICS) New York, USA: UNICEF, 2014. https://www.unicef.org/statistics/index_24302. html (accessed 24 October 2019).

17. Hosmer DWJ, Lemeshow S, Sturdivant RX. Model-building Strategies and Methods for Logistic Regression. Applied Logistic Regression. Wiley Series in Probability and Statistics. 3rd ed. Hoboken, NJ: John Wiley \& Sons, 2013.

18. Aliyu AA, Dahiru T. Factors associated with safe disposal practices of child's faeces in Nigeria: Evidence from 2013 Nigeria Demographic and Health Survey. Niger Med J 2019;60(4):198-204. https://doi.org/10.4103/nmj.NMJ_3_19 
19. Morita T, Godfrey S, George CM. A systematic review of evidence on the effectiveness of safe child faeces disposal interventions. Trop Med Int Health 2016;21(11):1403-1419. https://doi.org/10.1111/tmi.12773

20. World Bank. Water and Sanitation Program: Child Feces Disposal Country Profile. Washington, D.C.: World Bank Group, 2014. http://documents.worldbank.org/ curated/en/932721468185039386/Madagascar-Child-feces-disposal (accessed 16 April 2020)

21. Majorin F, Torondel B, Routray P, Rout M, Clasen T. Identifying potential sources of exposure along the child feces management pathway: A cross-sectional study among urban slums in Odisha, India. Am J Trop Med Hyg 2017;97(3):861-869. https://doi.org/10.4269/ajtmh.16-0688

22. Ps P, Sahoo SK, Biswas D, Dasgupta A. Unsafe disposal of child faeces: A community-based study in a rural block in west Bengal, India. J Prev Med Public Health 2016;49(5):323-328. https://doi.org/10.3961/jpmph.16.020

23. UNICEF, WSP, World Bank Group. Child Feces Disposal in Madagascar. 2014. https://www.wsp.org/sites/wsp.org/files/publications/WSP-Madagascar-CFDProfile.pdf (accessed 7 October 2019).

24. Clasen TF, Bostoen K, Schmidt WP, et al. Interventions to improve disposal of human excreta for preventing diarrhea. Cochrane Database of Systematic Reviews 2010;2010(6):Cd007180. https://doi.org/10.1002/14651858.cd007180.pub2

25. Cronin AA, Sebayang SK, Torlesse H, Nandy R. Association of safe disposal of child feces and reported diarrhea in Indonesia: Need for stronger focus on a neglected risk. Int J Environl Res Pub Health 2016;13(3). https://doi.org/10.3390/ ijerph13030310

26. Majorin F, Freeman MC, Barnard S, Routray P, Boisson S, Clasen T. Child feces disposal practices in rural Orissa: A cross sectional study. PloS One 2014;9(2):e89551-e. https://doi.org/10.1371/journal.pone.0089551
27. Bawankule R, Singh A, Kumar K, Pedgaonkar S. Disposal of children's stools and its association with childhood diarrhea in India. BMC Public Health 2017;17(1):12. https://doi.org/10.1186/s12889-016-3948-2

28. Bauza V, Reese H, Routray P, Clasen T. Child defecation and feces disposal practices and determinants among households after a combined householdlevel piped water and sanitation intervention in rural Odisha, India. Am J Trop Med Hyg 2019;100(4):1013-1021. https://doi.org/10.4269/ajtmh.18-0840

29. Traoré E, Cousens S, Curtis V, et al. Child defecation behavior, stool disposal practices, and childhood diarrhea in Burkina Faso: Results from a case-control study. J Epidemiol Comm Health 1994;48(3):270-275. https://doi.org/10.1136/ jech.48.3.270

30. Ohwo O. Dimensions of inequality in urban and rural water, sanitation, and hygiene services in Sub-Saharan Africa. Eur Sci J 2019;15(8). https:// doi.10.19044/esj.2019.v15n8p144

31. Irianti S, Prasetyoputra P. Unsafe disposal of child feces in Indonesia. J Ekologi Kesehatan 2018;17:1-10. https://doi.org/10.22435/jek.17.1.101.1-10

32. Carlson MDA, Morrison RS. Study design, precision, and validity in observational studies. J Palliat Med 2009;12(1):77-82. https://doi. org/10.1089\%2Fjpm.2008.9690

Accepted 9 June 2020 